\section{Vol. 38, Issue 4, August 2011}

Editorial

229 Impact of Bacterial Contamination on Blood Supply

Walther-Wenke, G (Münster); Schmidt, M. (Frankfurt/M.)

Review Articles

231 Effect of Safety Measures on Bacterial Contamination Rates of Blood Components in Germany

Walther-Wenke, G. (Münster); Däubener, W. (Düsseldorf); Heiden, M. (Langen); Hoch, J. (Bonn); Hornei, B. (Leverkusen); Volkers, P. (Langen); Wirsing von König, C.-H. (Krefeld); Working Party on Bacteria Safety in Transfusion Medicine of the National Advisory Committee Blood of the German Federal Ministry of Health (Arbeitskreis Blut), Berlin, Germany

236 Pathogenicity of Bacteria Contaminating Blood Products

Gatermann, S.G. (Bochum)

239 Bacterial Pre-Release Testing of Platelets the Australian Red Cross Blood Service Clinical Experience

Borosak, M.E.; Woods, E.M. (South Melbourne)

242 Laboratory Evaluation of the Effectiveness of Pathogen Reduction Procedures for Bacteria Müller, T.H. (Springe); Montag, T. (Langen); Seltsam, A.W. (Springe)

\section{Original Articles}

25110 Years Experience with Bacterial Screening of Platelet Concentrates in the Netherlands de Korte, D. (Amsterdam)

255 Interventions Implemented to Reduce the Risk of Transmission of Bacteria by Transfusion in the English National Blood Service McDonald, C.P. (London)

\section{Band 38, Heft 4, August 2011}

Editorial

229 Einfluss der bakteriellen Kontamination auf die Blutversorgung

Walther-Wenke, G (Münster); Schmidt, M. (Frankfurt/M.)

\section{Übersichtsarbeiten}

231 Der Einfluss von Sicherheitsmaßnahmen auf die bakteriellen Kontaminationsraten von Blutkomponenten in Deutschland

Walther-Wenke, G. (Münster); Däubener, W. (Düsseldorf); Heiden, M. (Langen); Hoch, J. (Bonn); Hornei, B. (Leverkusen); Volkers, P. (Langen); Wirsing von König, C.-H. (Krefeld); Working Party on Bacteria Safety in Transfusion Medicine of the National Advisory Committee Blood of the German Federal Ministry of Health (Arbeitskreis Blut), Berlin, Germany

236 Pathogenität bakterieller Kontaminationen von Blutprodukten

Gatermann, S.G. (Bochum)

239 Bakterielle Thrombozytentestung vor Freigabe klinische Erfahrungen des Blutspendedienstes des Australian Red Cross

Borosak, M.E.; Woods, E.M. (South Melbourne)

242 Untersuchung der Wirksamkeit von Pathogenreduktionsverfahren für Bakterien Müller, T.H. (Springe); Montag, T. (Langen); Seltsam, A.W. (Springe)

\section{Originalarbeiten}

25110 Jahre Erfahrung mit dem bakteriellen Screening von Thrombozytenkonzentraten in den Niederlanden

de Korte, D. (Amsterdam)

255 Umgesetzte Maßnahmen zur Reduzierung des Risikos von Bakterienübertragungen durch Transfusionen im englischen National Blood Service

McDonald, C.P. (London)

\section{KARGER}

Fax +49 7614520714

Information@Karger.de

www.karger.com 


\section{Vol. 38, Issue 4, August 2011}

259 Implementation of Bacterial Detection Methods into Blood Donor Screening - Overview of Different Technologies

Schmidt, M.; Sireis, W.; Seifried, E. (Frankfurt/M.)

266 Transfusion-Transmitted Bacterial Infections Haemovigilance Data of German Blood Establishments (1997-2010)

Funk, M.B.; Lohmann, A.; Guenay, S.; Henseler, O.; Heiden, M.; Hanschmann, K.M.O.; Keller-Stanislawski, B. (Langen)

272 Prolonged Blood Storage Does Not Effect Survival in an Animal Model of Hemorrhagic Shock

Abadi, U. (Kfar Saba/Tel Aviv); Butenero, G.; Kogan, T.

(Kfar Saba); Ziv, O. (Tel Aviv); Paran, H. (Tel Aviv/Kfar Saba); Ellis, M.H. (Kfar Saba/Tel Aviv)

277 News / Ticker

278 Innovations

280 Meetings and Conferences

238 Imprint

\section{Band 38, Heft 4, August 2011}

259 Implementierung von bakteriellen Nachweismethoden in das Blutspender-Screening Überblick über verschiedene Technologien

Schmidt, M.; Sireis, W.; Seifried, E. (Frankfurt/M.)

266 Transfusionsbedingte bakterielle Infektionen Hämovigilanzdaten der Deutschen Blutspendeeinrichtungen (1997-2010)

Funk, M.B.; Lohmann, A.; Guenay, S.; Henseler, O.; Heiden, M.; Hanschmann, K.M.O.; Keller-Stanislawski, B. (Langen)

272 Verlängerte Blutlagerung hat keinen Einfluss auf das Überleben in einem Tiermodell für hämorrhagischen Schock

Abadi, U. (Kfar Saba/Tel Aviv); Butenero, G.; Kogan, T. (Kfar Saba); Ziv, O. (Tel Aviv); Paran, H. (Tel Aviv/Kfar Saba); Ellis, M.H. (Kfar Saba/Tel Aviv)

277 News / Ticker

278 Innovationen

280 Tagungen und Kongresse

238 Impressum

\section{KARGER}

๑ 2011 S. Karger GmbH, Freiburg

Fax +497614520714 